\title{
The AMC Linear Disability Score (ALDS): a cross-sectional study with a new generic instrument to measure disability applied to patients with peripheral arterial disease

\author{
Rosemarie Met ${ }^{1}$, Jim A Reekers*1, Mark JW Koelemay², Dink A Legemate ${ }^{2}$ \\ and Rob J de Haan ${ }^{3}$
}

Address: ${ }^{1}$ Department of Radiology, Academic Medical Center, Meibergdreef 9, 1105 AZ, Amsterdam, the Netherlands, ${ }^{2}$ Department of Vascular Surgery, Academic Medical Center, Meibergdreef 9, 1105 AZ, Amsterdam, the Netherlands and ${ }^{3}$ Department of Clinical Epidemiology and Biostatistics, Academic Medical Center, Meibergdreef 9, 1105 AZ, Amsterdam, the Netherlands

Email: Rosemarie Met - r.met@amc.uva.nl; Jim A Reekers* - j.a.reekers@amc.uva.nl; Mark JW Koelemay - m.j.koelemaij@amc.uva.nl; Dink A Legemate - d.a.legemate@amc.uva.nl; Rob J de Haan - robjdehaan@gmail.com

* Corresponding author

Published: 12 October 2009

Health and Quality of Life Outcomes 2009, 7:88 doi:10.1 186/1477-7525-7-88

This article is available from: http://www.hqlo.com/content/7/1/88

(C) 2009 Met et al; licensee BioMed Central Ltd.

This is an Open Access article distributed under the terms of the Creative Commons Attribution License (http://creativecommons.org/licenses/by/2.0), which permits unrestricted use, distribution, and reproduction in any medium, provided the original work is properly cited.
Received: 7 April 2009

Accepted: 12 October 2009

\begin{abstract}
Background: The AMC Linear Disability Score (ALDS) is a calibrated generic itembank to measure the level of physical disability in patients with chronic diseases. The ALDS has already been validated in different patient populations suffering from chronic diseases. The aim of this study was to assess the clinimetric properties of the ALDS in patients with peripheral arterial disease.

Methods: Patients with intermittent claudication (IC) and critical limb ischemia (CLI) presenting from January 2007 through November 2007 were included. Risk factors for atherosclerosis, ankle/ brachial index and toe pressure, the Vascular Quality of Life Questionnaire (VascuQol), and the ALDS were recorded. To compare ALDS and VascuQol scores between the two patient groups, an unpaired $t$-test was used. Correlations were determined between VascuQol, ALDS and pressure measurements.

Results: Sixty-two patients were included ( 44 male, mean \pm sd age was $68 \pm$ II years) with IC (n $=26)$ and $\mathrm{CLI}(\mathrm{n}=36)$. The average ALDS was significantly higher in patients with IC $(80, \pm 10)$ compared to patients with CLI $(64, \pm 18)$. Internal reliability consistency of the ALDS expressed as Cronbach's $\alpha$ coefficient was excellent $(\alpha>0.90)$. There was a strong convergent correlation between the ALDS and the disability related Activity domain of the VascuQol $(r=0.64)$.
\end{abstract}

Conclusion: The ALDS is a promising clinimetric instrument to measure disability in patients with various stages of peripheral arterial disease.

\section{Background}

The impact of a disease on a patient's quality of life and level of activities of daily life (ADL) is an important outcome measure in clinical studies [1]. It is well known that perceived quality of life and ADL are significantly impaired in individuals with peripheral arterial disease (PAD) [2-5].

There are several instruments available to measure quality of life in patients with PAD. Both generic instruments, 
such as the Short-Form 36 (SF36), the Sickness Impact Profile, and the Nottingham Health Profile [6], and disease-specific instruments like the Vascular Quality of Life Questionnaire (VascuQol) and the Claudication Scale (CLAU-S) are frequently used [7,8]. A limitation of these instruments is that they do not focus on level of ADL in terms of self-care, dressing, indoors and outdoors activities, and housekeeping management. Measuring this level of disability is useful, since it is more closely related to impairments and the course of the disease itself. Within the field of PAD, however, there are no instruments available which specifically address the patient's level of ADL.

The AMC (Academic Medical Center) Linear Disability Score (ALDS) is a recently developed generic itembank which measures disability, as expressed by the ability to perform ADL $[9,10]$. In contrast to the widely used sum score-based questionnaires, the ALDS itembank was developed within the flexible framework of the itemresponse theory (IRT). The ALDS has already been validated in a large, mixed patient population [11] and in patients suffering from rheumatoid arthritis, stroke and Parkinson's disease [12-14]. The objective of this study was to evaluate the clinimetric properties of the ALDS in patients with different stages of PAD.

\section{Methods}

\section{Patients}

A convenient sample of 62 patients was included in this prospective study. We deliberately selected patients with different stages of disease to evaluate the ALDS for the whole spectrum of PAD. Patients visited the vascular laboratory or vascular nursing ward of our hospital between January 2007 and November 2007. All patients were diagnosed with either intermittent claudication (IC; Rutherford category 1, 2 or 3) or chronic critical limb ischemia (CLI; Rutherford category 4, 5 or 6) [15]. The clinical diagnosis was confirmed by perfusion parameters, such as ankle/brachial index (ABI) and toepressure (TP). Patients were assessed and interviewed by one of the authors (RM). Assessments took place before intervention, consisting of exercise training, revascularization or amputation. The study was approved by the local Institutional Review Board.

\section{Assessments}

We recorded risk factors for atherosclerosis, namely diabetes mellitus, hypertension, smoking, renal failure, hypercholesterolemia, history of coronary artery disease or cerebrovascular disease. In patients with IC, we measured $\mathrm{ABI}$ at rest and after exercise. In patients with CLI, we measured $\mathrm{ABI}$ at rest and TP.

Quality of life was measured using the VascuQol, which is a sum-score based instrument. The questionnaire consists of 25 items on five domains, i.e. Pain (4 items), Activity (8), Emotional (7), Symptoms (4) and Social (2). Each item is rated as a seven point response scale, with a score of one being the worst and a score of seven the best possible. The total average score is the sum of all 25 items scores divided by 25 . For each separate domain an average score can be calculated (sum of all items of one domain divided by the number of items of that domain). So, both the overall score as well as the scores per domain range from one to seven [16]. The VascuQol has shown to be a reliable and valid instrument for assessment of QoL in patients with PAD $[7,17]$.

Disability status was evaluated using the ALDS. For the psychometrical details of IRT in relation to the ALDS, see Additional file 1 . The current version of the ALDS itembank consists of 77 items, ranging from very easy (e.g., get out of bed into a chair) to relatively difficult (e.g., walk for more than 15 minutes) [see Additional file 2]. Initially, the ALDS was developed within a dichotomous IRT model with two response options 'I can carry out the activity' and 'I cannot carry out the activity' [9]. However, the dichotomous rating scales were disliked by some respondents as they are perceived as too restrictive. Therefore, the option 'with difficulty' has been added. Currently, each item has three response options, but the response options 'can carry out' and 'can carry out, but with difficulty' are analysed as one response category. In the case that a patient has never performed the activity or answers that he does not know, 'Not applicable' is recorded. The original units of the ALDS scale are (logistic) regression coefficients, expressed in logits. To make the results easier to interpret these scores are linearly transformed into values between 0 and 100. Lower scores represent more disability.

A major strength of an IRT itembank is that researchers, using their clinical judgment, can make their own selections of items from the itembank that are applicable to the population they are investigating. By using a small number of items tailored to the expected ADL level of patients, a detailed clinical picture can be obtained without the need to have all the questions answered by the patient. Even if different sets of items are used for different patient groups, ALDS scores can still be compared because all items are derived from the calibrated itembank. In this way the ALDS can be used to assess patients with a wide range of conditions and levels of functional status.

The methodology [9], the psychometrics of the ALDS in terms of dealing with missing data [18], differences between item measurement characteristics of the itembank in relation to age and sex [19] and the metric properties of ALDS items in mixed types of patient groups [11$14]$, as well as the statistical power to detect given effect 
sizes in clinical trials using IRT outcome scales [20] have been examined in depth.

From the ALDS itembank, two questionnaires were composed in this study: one questionnaire for claudicants (29 items), and one questionnaire for patients with critical limb ischemia (27 items). Twenty-three items were in common, covering the whole range of the ALDS itembank. Besides these common items, the claudication questionnaire encompassed six additional, relatively more difficult activities, whereas in the critical limb ischemia questionnaire four extra, relatively easier activities were offered. Selecting a representative range of items is essential to prevent floor and ceiling effects. For example, presenting a slightly disabled patient only items between an ALDS of 10 to 50, the maximum achieved ALDS will be 50 (ceiling effect), whereas with items ranging from 0 through 100, the 'real score' (for example 80) can be achieved. Since the ALDS is based on the IRT, the score is not influenced by the selected items [9]. For the complete ALDS item bank and the selected items in this study, see Additional file 2.

\section{Clinimetric evaluation}

The clinical measurement properties of the ALDS were evaluated in terms of internal consistency reliability, construct validity and clinical validity.

Internal consistency reliability refers to the statistical coherence of the scale items. One measure of internal consistency is the Cronbach's $\alpha$ coefficient, which is based on the (weighted) average correlation of items within a scale $[21,22]$. Internal consistency is considered to be good if $\alpha$ $\geq 0.80$ [23]. We also calculated item-total correlations which represent the correlation of a single item with the sum of all other items. Correlations $\geq 0.40$ were conservatively considered to be sufficient.

Construct validity concerns whether the new scale corresponds with other instruments measuring the same health concept and instruments measuring different aspects of health. We assumed that in order for the ALDS to be valid, the ALDS scores had to show a decreasing pattern of associations, with the highest correlation with the disability related Activity domain of the VascuQol, intermediate correlations with the VascuQol subscales Symptom, Pain, Emotional and Social, and the lowest with the impairments in terms of $\mathrm{ABI}$ and TP $[24,25]$.

Clinical validity (also known as known-groups validity) refers to the ability of an instrument to discriminate between patient groups with known differences in clinical status. In this study, clinical validity was investigated by comparing the ALDS between patients with IC and patients with CLI, with ALDS scores to be expected higher in patients with IC than in patients with CLI.

The VascuQol was used as benchmark and therefore the analyses focusing the association between functional health and the vascular parameters and the mean score differences between patients with IC and CLI, were also done for the VascuQol and its Activity domain.

\section{Statistical analysis}

Patient characteristics and outcome scores were summarized using descriptive statistics. Distribution of the data was tested with a histogram and the Kolmogorov-Smirnov test. In case of discrepancy between both methods, we regarded the data as not normally distributed. ALDS outcome scores were calculated using a dichotomous IRT model, based on previously published item properties [11] and algorithms implemented in BILOG-MG (version 3.0) and SPSS version 14.0 (SPSS Inc, Chicago, Illinois). In this approach the response options 'can carry out' and 'can carry out, but with difficulty' are analysed as one response category. ALDS items which were rated 'Not applicable' were statistically considered as if they were not presented to that patient [18].

Cronbach's $\alpha$ was obtained using a specific IRT method that allows for missing item responses. The average itemtotal correlation was calculated using a biserial correlation. Associations between the ALDS (and VascuQol) and other outcome measures were expressed in Pearsons's or Spearman's correlation coefficients, when appropriate. We labelled the strength of the association: correlation coefficients $r=0.00-0.19$ were regarded as very weak, $r=$ $0.20-0.39$ as weak, $r=0.40-0.59$ as moderate, $r=0.60$ 0.79 as strong and $r=0.80-1.00$ as very strong [26]. An unpaired $t$-test was used to compare ALDS and VascuQol scores between the two patients groups. Difference in mean scores between both diagnosis groups was expressed in Cohen's $d$ effect size, defined as the difference between the means divided by the pooled standard deviation. An effect size value between 0.50 and 0.80 is considered as a moderate difference, and $\geq 0.80$ as substantial [27].

\section{Results}

A total of 62 patients were included, 26 (42\%) with intermittent claudication (Rutherford 1 in 6 patients, Rutherford 2 in 13, and Rutherford 3 in 7 patients) and 36 (58\%) with critical limb ischemia (Rutherford 4 in 11 patients, Rutherford 5 in 17, and Rutherford 6 in 8 patients). The majority of the patients $(71 \%)$ were male and the mean age was $68( \pm 11)$ years. Table 1 shows the patient characteristics at time of assessment. The VascuQol Total score, the VascuQol domains Activity, Symptoms, Pain, Emotional and Social, and the ALDS were all normally distrib- 
Table I: Patient characteristics $(n=62)$ at assessment.

\begin{tabular}{|c|c|}
\hline Characteristics & Mean ( \pm sd) or median (range) or $n(\%)$ \\
\hline Gender, male & $44(7 \mid \%)$ \\
\hline Age & $68.4( \pm 11.4)$ \\
\hline \multicolumn{2}{|l|}{ Risk factors } \\
\hline Diabetes mellitus & $22(35 \%)$ \\
\hline Hypertension & $44(7 \mid \%)$ \\
\hline Current or former smoker & $51(82 \%)$ \\
\hline Renal failure & $16(26 \%)$ \\
\hline Hypercholesterolemia & $15(24 \%)$ \\
\hline History of coronary artery disease & $23(37 \%)$ \\
\hline History of stroke & $12(19 \%)$ \\
\hline \multicolumn{2}{|l|}{ Fontaine stage } \\
\hline II; intermittent claudication & $26(42 \%)$ \\
\hline III or IV; critical limb ischemia & $36(58 \%)$ \\
\hline \multicolumn{2}{|l|}{ Definitive treatment } \\
\hline Conservative & $15(24 \%)$ \\
\hline Endovascular revascularization & $36(58 \%))$ \\
\hline Surgical revascularization & $8(13 \%)$ \\
\hline Amputation & $3(5 \%)$ \\
\hline $\begin{array}{l}\mathrm{ABI} \text { at rest } \\
\text { (in patients with } \mathrm{CLI} \text { ) }\end{array}$ & $0.35(0-0.59)$ \\
\hline $\begin{array}{l}\text { Decrease } A B I \text { after exercise } \\
\text { (in patients with IC) }\end{array}$ & $0.28(0.09-0.55)$ \\
\hline $\begin{array}{l}\text { Toe pressure } \mathrm{mmHg} \\
\text { (in patients with CLI) }\end{array}$ & $19(0-67)$ \\
\hline ALDS & $71( \pm 17)$ \\
\hline VascuQol total & $3.7( \pm 1.3)$ \\
\hline
\end{tabular}

alndicates difference in $\mathrm{ABI}$ before and after exercise

uted (histograms showed normal distribution and Kolmogorov-Smirnov test p-values $>0.10$ ). The decrease in $\mathrm{ABI}$, resting $\mathrm{ABI}$, and TP were considered not normally distributed (although the Kolmogorov-Smirnov test had a p-value $>0.05$, the histograms did not show a Gaussian distribution). 
The internal consistency reliability of the ALDS in terms of Cronbach's $\alpha$ and item-total correlation turned out to be good; $\alpha$ coefficient $>0.90$, average item-total correlation: 0.75 .

Table 2 presents the correlations between the ALDS scores and the various subscale scores of the VascuQol. Convergent validity was confirmed with a relatively strong correlation $(r=0.64)$ between the ALDS and the disability related Activity domain of the VascuQol. Moderate correlations were observed between the ALDS and the subscales Symptom $(r=0.44)$ and Social $(r=0.52)$, whereas the ALDS was weakly associated with the Emotional and Pain domains ( 0.30 and 0.28 ). Table 3 presents the correlations between the ALDS and the VascuQol scores on the one hand and decrease in ABI, resting ABI, and TP. These correlations were (very) weak ( $r$ range: 0 - 0.38).

Clinical validity is shown in Table 4 . The ALDS score was significantly higher in patients with claudication (ALDS score 80 ) than in patients with CLI (ALDS score 64). Similar results were obtained for the VascuQol total score (4.5 in patients with claudication and 3.1 in patients with CLI) and the VascuQol domain Activity (4.0 in patients with claudication versus 2.4 in patients with CLI). The effect size values for the ALDS and the VascuQol total and subscale scores were $d=0.97,1.13$, and 1.08 , respectively.

\section{Discussion}

In this study, we showed that the ALDS has promising clinical measurement properties to assess the level of disability in patients with PAD. The ALDS demonstrated convincing statistical coherence and was higher in patients with milder disease, who are expected to be less disabled. We could not compare the ALDS with a gold standard, as there is not such an instrument measuring disability available for patients with PAD. A recent study, comparing three questionnaires - two generic questionnaires (the EuroQol and SF-36) and one disease-specific question-

Table 2: Construct validity; Pearson's correlation coefficients between the ALDS and the VascuQol $(n=62)$.

\begin{tabular}{lll}
\hline \multicolumn{3}{l}{ ALDS } \\
\hline VascuQol; Total score & $r=0.55$ & $\mathrm{P}=<0.00 \mathrm{I}$ \\
\hline VascuQol; domain Activity & $r=0.64$ & $\mathrm{P}=<0.00 \mathrm{I}$ \\
\hline VascuQol; domain Symptoms & $r=0.44$ & $\mathrm{P}=<0.00 \mathrm{I}$ \\
\hline VascuQol; domain Pain & $r=0.28$ & $\mathrm{P}=0.03$ \\
\hline VascuQol; domain Emotional & $r=0.30$ & $\mathrm{P}=0.02$ \\
\hline VascuQol; domain Social & $r=0.52$ & $\mathrm{P}=<0.00 \mathrm{I}$ \\
\hline
\end{tabular}

naire (the VascuQol) - showed that the VascuQol is the preferred questionnaire for measuring QoL in patients with PAD [7]. For this reason, we used the VascuQol, and especially its Activity domain, as benchmark for the ALDS analyses. Construct validity was confirmed by a relatively strong association of the ALDS with the domain Activity of the VascuQol, which also measures aspects of physical disability. Construct validity was further supported by decreasing correlations with the other non-disability domains of the VascuQol and the clinical indicators of lower limb ischemia.

The weak correlation between the ALDS (and VascuQol) and clinical indicators of lower limb perfusion in terms of $\mathrm{ABI}$ and toe pressure may seem remarkable, but is in line with previous studies in other populations showing that objective disease indicators are not always clearly reflected in (subjective) aspects of functional health [28]. This seems to be true also for patients with PAD. Long et al did not find a correlation between the $\mathrm{ABI}$, the Walking Impairment Questionnaire (WIQ, measuring mobility) and the Physical Component score of the SF36 in patients with symptoms of PAD [24]. Other studies also failed to demonstrate a correlation between the ABI and the SF36 Physical functioning domain and the EuroQol $[25,29,30]$.

The WIQ [31,32] is one of the few instruments that assesses the level of disability in terms of mobility. This questionnaire focuses mainly on walking ability, divided in four subcategories: pain, distance, walking speed and stair climbing. The WIQ has been developed specifically for patients with IC, and does not cover the whole spectrum of PAD. The ALDS carries the advantage that it can be used for both patients with IC and CLI. Moreover, the ALDS focuses on the whole spectrum of basic and complex activities of daily life, including self-care, different mobility levels, housekeeping and outdoor activities.

Most clinicians are used to work with traditional outcome instruments based on sum scores. Although adding up individual item scores to a total score is comprehensibly in use, several problems are associated with this approach. Firstly, all items of the questionnaire have to be presented to patients in order to obtain a summated score. This implies that for a detailed picture of the patient, a long questionnaire encompassing many questions, is needed, increasing patient burden and research effort. This inefficiency has led researchers to shorten health measurement instruments, resulting in less precise scales. Secondly, the ordinal nature of summated scores implies that a given difference in scores at one point on the scale does not necessarily represent the same amount of functional change as an identical difference at another point on the scale. Following growing dissatisfaction with this 'classical' 
Table 3: Construct validity; Spearman correlation coefficients between the ALDS, the VascuQol and clinical indicators ( $n=62$ ).

\begin{tabular}{|c|c|c|c|c|c|c|}
\hline & ALDS & & $\begin{array}{l}\text { VascuQol } \\
\text { (Activity) }\end{array}$ & & $\begin{array}{l}\text { VascuQol } \\
\text { (Total) }\end{array}$ & \\
\hline $\begin{array}{l}\text { Decrease } A B I \text { after exercise } \\
\text { (in patients with IC) }\end{array}$ & $r=0.16$ & $P=0.50$ & $r=0.00$ & $P=1.00$ & $r=0.16$ & $P=0.50$ \\
\hline $\begin{array}{l}\mathrm{ABI} \text { at rest } \\
\text { (in patients with } \mathrm{CLI} \text { ) }\end{array}$ & $r=0.14$ & $P=0.49$ & $r=0.02$ & $P=0.92$ & $r=0.20$ & $P=0.33$ \\
\hline $\begin{array}{l}\text { Toe pressure } \\
\text { (in patients with CLI) }\end{array}$ & $r=0.19$ & $P=0.37$ & $r=0.38$ & $P=0.06$ & $r=0.18$ & $P=0.38$ \\
\hline
\end{tabular}

approach, IRT has been introduced to overcome these methodological problems [33].

Measurement instruments based on the IRT have some specific advantages. A clinician can select a set of items which is applicable to the population that is investigated, not all items from the itembank are needed to obtain a score. For example, very easy items do not have to be presented to minor disabled patients. Therefore, the ALDS can be administered in a time-efficient way (in this study between 5-10 minutes). There are some essential aspects to be aware of. As mentioned before, to prevent floor and ceiling effects (i.e. the extent to which respondents score at the bottom or top of a scale) it is very important to ask a patient activities he is able to do and also activities he is not able to do, instead of asking too difficult or too easy questions. If one does so, it does not matter which questions are picked to assess patient's disability level, since the ALDS is based on the IRT. The latter is, as we found out, the most difficult part of the ALDS to appreciate by those who are used to work with the traditional questionnaires.

Some limitations of this study should be recognized. A repeated measurement with an instrument in the same patient or using different interviewers must give more or less the same outcome in the case of an unchanged patient. In the present study, we did not analyze test-retest or between-interviewer reliability. Yet, in a previous study with the ALDS in patients with rheumatoid arthritis, excellent test-retest reliability was found with an Intra Class Coefficient of 0.93 [14]. Other disadvantages are that the ALDS interviewer was not blinded to patient characteristics and that we studied a relatively small number of patients. This must be taking into account when interpreting the results.

As the objective of this validation study was to investigate the measurement properties of ALDS in patients with different stages of PAD, we deliberately selected patients for inclusion, instead of consecutive enrolment, to guarantee that the whole spectrum of PAD was represented in our sample. There is no reason to assume that this non-consecutive inclusion has influenced our psychometrical findings.

\section{Conclusion}

Our study must be seen as a first step in the process of validation of the ALDS in patients with PAD. Further evaluation of this instrument, especially with regard to the testretest and between-reviewer reliability and the presence of floor and ceiling effects, is needed in a larger consecutive patient population. We think the instrument could be particularly useful in research, to measure the effect of treatment. Before this, the responsiveness of the ALDS to health change over time must be investigated. In conclu-

Table 4: Clinical validity: ALDS and VascuQol score of patients with IC $(n=26)$ and CLI $(n=36)$.

\begin{tabular}{|c|c|c|c|c|c|}
\hline & Patient groups & & & & \\
\hline & Intermittent claudication & Critical limb ischemia & $\begin{array}{l}\text { Difference } \\
\text { ( } 95 \% \text { confidence interval) }\end{array}$ & & \\
\hline ALDS & $80( \pm 10)$ & $64( \pm 18)$ & $16(8-24)$ & $\mathrm{P}<.00 \mathrm{I}^{\mathrm{a}}$ & $d=0.97$ \\
\hline VascuQol (Activity) & $4.0( \pm 1.6)$ & $2.4( \pm 1.1)$ & $1.7(0.9-2.4)$ & $\mathrm{P}<.00 \mathrm{I}^{\mathrm{a}}$ & $d=1.08$ \\
\hline VascuQol (Total) & $4.5( \pm 1.1)$ & $3.1( \pm 1.0)$ & $1.4(0.9-2.0)$ & $\mathrm{P}<.00 \mathrm{I}^{\mathrm{a}}$ & $d=1.13$ \\
\hline
\end{tabular}

aUnpaired $t$-test; $d=$ Cohen's effect size 
sion, the results of this pilot study show that the ALDS has promising metric properties and is a potentially useful tool to measure activities of daily life in patients with PAD.

\section{Abbreviations}

ABI: Ankle/brachial index; ADL: Activities of daily life; ALDS: AMC Linear Disability Score; AMC: Academic Medical Center; CLAU-S: Claudication Scale; CLI: Critical limb ischemia; IC: Intermittent claudication; IRT: Item response theory; PAD: Peripheral arterial disease; SD: Standard deviation; SF36: Short-Form 36; TP: Toe pressure; VascuQol: Vascular Quality of Life Questionnaire; WIQ: Walking impairment questionnaire.

\section{Competing interests}

The authors declare that they have no competing interests.

\section{Authors' contributions}

RM has made substantial contributions to design of the study and acquisition and analysis of data, and drafting of the manuscript, JAR has been involved in the design of the study and interpretation of data, as well as in drafting the manuscript, MJWK was involved in interpretation of data and drafting the manuscript, DAL contributed to the design and revised the manuscript critically, RJH was involved in design, analysis and interpretation of the data and drafting of the manuscript. All authors read and approved the final manuscript.

\section{Additional material}

\section{Additional file 1}

Methodology of the ALDS itembank. Data represent details about the construction of the ALDS itembank.

Click here for file

[http://www.biomedcentral.com/content/supplementary/1477-

7525-7-88-S1.DOC]

\section{Additional file 2}

ALDS itembank containing 77 items. Data represent a list of all 77 items of the ALDS itembank, the items we used in our study are marked. Click here for file

[http://www.biomedcentral.com/content/supplementary/14777525-7-88-S2.DOC]

\section{Acknowledgements}

None.

\section{References}

I. World Health Organization: International Classification of Functioning, Disability, and Health. [http://www3.who.int/icf/icftem plate.cfm].

2. Regensteiner JG, Hiatt WR, Coll JR, Criqui MH, Treat-Jacobson D, McDermott MM, Hirsch AT: The impact of peripheral arterial disease on health-related quality of life in the Peripheral
Arterial Disease Awareness, Risk, and Treatment: New Resources for Survival (PARTNERS) Program. Vasc Med 2008, I 3:15-24.

3. McDermott MM, Mehta S, Liu K, Guralnik JM, Martin GJ, Criqui MH Greenland P: Leg symptoms, the ankle-brachial index, and walking ability in patients with peripheral arterial disease. Gen Intern Med 1999, I4:173-I8I.

4. Brach JS, Solomon C, Naydeck BL, Sutton-Tyrrell K, Enright PL, Jenny NS, Chaves PM, Newman AB, Cardiovascular Health Study Research Group: Incident physical disability in people with lower extremity peripheral arterial disease: the role of cardiovascular disease. J Am Geriatr Soc 2008, 56: 1037-1044.

5. Kuo $\mathrm{HK}, \mathrm{Yu} \mathrm{YH}$ : The relation of peripheral arterial disease to leg force, gait speed, and functional dependence among older adults. J Gerontol A Biol Sci Med Sci 2008, 63:384-390.

6. Landry GJ: Functional outcome of critical limb ischemia. J Vasc Surg 2007, 45: |4|a-|48a.

7. De Vries M, Ouwendijk R, Kessels AG, De Haan MW, Flobbe K, Hunink MG, Van Engelshoven JM, Nelemans PJ: Comparison of generic and disease-specific questionnaires for the assessment of quality of life in patients with peripheral arterial disease. J Vasc Surg 2005, 41:26I-268.

8. Mehta T, Venkata Subramaniam A, Chetter I, McCollum P: Diseasespecific quality of life assessment in intermittent claudication: review. Eur J Vasc Endovasc Surg 2003, 25:202-8.

9. Holman R, Lindeboom R, Glas CA, Vermeulen M, De Haan RJ: Constructing an item bank using item response theory: the $A M C$ Linear Disability Score project. Health Serv Outcomes Res Methodol 2003, 4:19-33.

10. De Haan RJ, Vermeulen M, Holman R, Lindeboom R: Measuring the functional status of patients in clinical trials using modern clinimetric methods [Dutch]. Ned Tijdschr Geneeskd 2002, | 46:606-6II.

II. Holman R, Weisscher N, Glas CA, Dijkgraaf MG, Vermeulen M, De Haan RJ, Lindeboom R: The Academic Medical Center Linear Disability Score (ALDS) item bank: item response theory analysis in a mixed patient population. Health Qual Life Outcomes 2005, 3:83.

12. Weisscher N, Wijbrandts CA, De Haan R, Glas CA, Vermeulen M, Tak PP: The Academic Medical Center Linear Disability Score item bank: psychometric properties of a new generic disability measure in rheumatoid arthritis. J Rheumatol 2007, 34: $1222-1228$.

13. Weisscher N, Vermeulen M, Glas CA, Roos YB, De Haan RJ: The AMC Linear Disability Score itembank: a new generic disability measure in stroke. 2008:8I-92 [http://dare.uva.nl/record/ 270674]. Thesis: The AMC Linear Disability Score (ALDS): Measuring disability in clinical studies. Amsterdam

14. Weisscher N, Post B, De Haan RJ, Glas CA, Speelman JD, Vermeulen $M$ : The AMC linear disability score in patients with newly diagnosed Parkinson disease. Neurology 2007, 69:2I55-2I6I.

15. Rutherford RB, Baker JD, Ernst C, Johnston KW, Porter JM, Ahn S, Jones DN: Recommended standards for reports dealing with lower extremity ischemia: revised version. J Vasc Surg 1997, 26:517-538

16. Morgan MB, Crayford T, Murrin B, Fraser SC: Developing the Vascular Quality of Life Questionnaire: a new disease-specific quality of life measure for use in lower limb ischemia. J Vasc Surg 200I, 33:679-687.

17. Nguyen LL, Moneta GL, Conte MS, Bandyk DF, Clowes AW, Seely BL: Prospective multicenter study of quality of life before and after lower extremity vein bypass in 1404 patients with critical limb ischemia. J Vasc Surg 2006, 44:977-983.

18. Holman R, Glas CA: Modelling non-ignorable missing data mechanisms with item response theory models. Br J Math Stat Psychol 2005, 58: I-I7.

19. Holman R, Lindeboom R, De Haan RJ: Gender and age based differential item functioning in the AMC Linear Disability Score project. Quality of life newsletter 2004, 32: I-4.

20. Holman R, Glas CA, De Haan RJ: Power analysis in randomized clinical trials based on item response theory. Control Clin Trials 2003, 24:390-410.

21. Cronbach LJ: Coefficient alpha and the internal structure of tests. Psychometrika 1951, 16:297-333.

22. Bland JM, Altman DG: Cronbach's alpha. BMJ I997, 3 | 4:572.

23. Nunnally J: Psychometric theory New York: McGraw-Hill; 1978. 
24. Long J, Modrall JG, Parker BJ, Swann A, Welborn MB 3rd, Anthony T: Correlation between ankle-brachial index, symptoms, and health-related quality of life in patients with peripheral vascular disease. J Vasc Surg 2004, 39:723-727.

25. Izquierdo-Porrera AM, Gardner AW, Bradham DD, Montgomery PS, Sorkin JD, Powell CC, Katzel LI: Relationship between objective measures of peripheral arterial disease severity to selfreported quality of life in older adults with intermittent claudication. J Vasc Surg 2005, 41:625-630.

26. Swinscow TDV: Correlation and regression. Statistics at Square One 9th edition. 1997 [http://www.bmj.com/statsbk/ll.dtl]. University of Southampton: BMJ Publishing Group

27. Cohen J: Statistical power analysis for the behavioral sciences New York: Academic Press; 1977.

28. Weisscher N, De Haan RJ, Vermeulen M: The impact of diseaserelated impairments on disability and health-related quality of life: a systematic review. BMC Med Res Methodol 2007, 7:24.

29. Feinglass J, McCarthy WJ, Slavensky R, Manheim LM, Martin GJ: Effect of lower extremity blood pressure on physical functioning in patients who have intermittent claudication. J Vasc Surg 1996, 24:503-5I2.

30. Chetter IC, Dolan P, Spark JI, Scott DJA, Kester RC: Correlating clinical indicators of lower-limb ischaemia with quality of life. Cardiovasc Surg 1997, 5:361-366.

31. Regensteiner JG, Steiner JF, Panzer RJ, Hiatt WR: Evaluation of walking impairment by questionnaire in patients with peripheral arterial disease. J Vasc Med Biol 1990, 2:I42-I52.

32. McDermott MM, Liu K, Guralnik JM, Martin G], Criqui MH, Greenland $P$ : Measurement of walking endurance and walking velocity with questionnaire: validation of the walking impairment questionnaire in men and women with peripheral arterial disease. J Vasc Surg 1998, 28:1072-108I.

33. Linden WJ Van der, Hambleton RK: Handbook of Modern Item Response Theory New York: Springer; 1997.

Publish with Bio Med Central and every scientist can read your work free of charge

"BioMed Central will be the most significant development for disseminating the results of biomedical research in our lifetime. "

Sir Paul Nurse, Cancer Research UK

Your research papers will be:

- available free of charge to the entire biomedical community

- peer reviewed and published immediately upon acceptance

- cited in PubMed and archived on PubMed Central

- yours - you keep the copyright
BioMedcentral 